\title{
The Renaissance of High-Energy CID for Structural Elucidation of Complex Lipids: MALDI-TOF/RTOF-MS of Alkali Cationized Triacylglycerols
}

\author{
Ernst Pittenauer and Günter Allmaier \\ Institute of Chemical Technologies and Analytics, Vienna University of Technology, Vienna, Austria
}

Triacylglycerols were analyzed as cationized species $\left(\mathrm{Li}^{+}, \mathrm{Na}^{+}, \mathrm{K}^{+}\right)$by high-energy CID at 20 $\mathrm{keV}$ collisions utilizing MALDI-TOF/RTOF mass spectrometry. Precursor ions, based on [M + $\mathrm{Li}]^{+}$-adduct ions exhibited incomplete fragmentation in the high and low $\mathrm{m} / z$ region whereas $[\mathrm{M}+\mathrm{K}]^{+}$-adducts did not show useful fragmentation. Only sodiated precursor ions yielded product ion spectra with structurally diagnostic product ions across the whole $\mathrm{m} / \mathrm{z}$ range. The high $\mathrm{m} / \mathrm{z}$ region of the CID spectra is dominated by abundant charge-remote fragmentation of the fatty acid substituents. In favorable cases also positions of double bonds or of hydroxy groups of the fatty acid alkyl chains could be determined. A-type product ions represent the end products of these charge-remote fragmentations. B- and C-type product ions yield the fatty acid composition of individual triacylglycerol species based on loss of either one neutral fatty acid or one sodium carboxylate residue, respectively. Product ions allowing fatty acid substituent positional determination were present in the low $\mathrm{m} / \mathrm{z}$ range enabling identification of either the $s n-1 / s n-3$ substituents (E-, F-, and G-type ions) or the $s n-2$ substituent (J-type ion). These findings were demonstrated with synthetic triacylglycerols and plant oils such as cocoa butter, olive oil, and castor bean oil. Typical features of $20 \mathrm{keV}$ CID spectra of sodiated triacylglycerols obtained by MALDI-TOF/RTOF MS were an even distribution of product ions over the entire $\mathrm{m} / \mathrm{z}$ range and a mass accuracy of \pm 0.1 to $0.2 \mathrm{u}$. One limitation of the application of this technique is mainly the insufficient precursor ion gating after MS1 (gating window at 4 u) of species separated by 2 u. (J Am Soc Mass Spectrom 2009, 20, 1037-1047) (c) 2009 American Society for Mass Spectrometry

$\mathrm{R}$ ecent advances in the analysis of complex triacylglycerol mixtures as well as detailed structural analysis thereof have been achieved by atmospheric pressure chemical ionization (APCI)- [1-10], electrospray ionization (ESI)- [11-20], fast atom bombardment (FAB)- [21-26], plasma desorption (PD) [27], and vacuum matrix-assisted laser desorption/ionization (vMALDI) mass spectrometry [28-39] with and without prior chromatographic separation. Various types of mass spectrometric analyzers (single quadrupole, triple quadrupole, ion trap, sector, tandem sector, reflectron time-of-flight, and various hybrid instruments) were utilized for these analytes, enabling various tandem mass spectrometric experiments (tandemin-time, tandem-in-space) at different energy regimes for ion activation from low-energy (tens of eVs) to high-energy (up to $25 \mathrm{keV}$ ) collision-induced dissociation (CID) by selecting either $[\mathrm{M}+\mathrm{H}]^{+}$-ions as well as $\left[\mathrm{M}+\mathrm{NH}_{4}\right]^{+}$- or $[\mathrm{M}+\mathrm{Na}]^{+}$-adduct ions as precursors ions.

Address reprint requests to Dr. E. Pittenauer, Institute of Chemical Technologies and Analytics, Vienna University of Technology, Getreidemarkt 9/164-IAC, A-1060 Vienna, Austria. E-mail: ernst.pittenauer@tuwien.ac.at
Usually, $[\mathrm{M}+\mathrm{H}]^{+}$-ions of triacylglycerols are predominantly produced under APCI conditions [8], exhibiting several drawbacks for tandem mass spectrometric analysis: (1) only triacylglycerol species containing at least one (from 1 to 6 or even more) double bonds show abundant $[\mathrm{M}+\mathrm{H}]^{+}$-ions, (2) triacylglycerol species without any double bonds do not exhibit any [M + $\mathrm{H}]^{+}$-ions but, instead, strong in-source-produced fragmentation (protonation occurs most likely around double bonds), and (3) all triacylglycerols, independently of the number of double bonds or of the presence of hydroxyl groups, show significant in-source fragmentation. Based on this fragmentation behavior, $[\mathrm{M}+\mathrm{H}]^{+}$-ions are not ideal precursor ions suited for tandem mass spectrometric investigations.

In ESI-MS, typically $\left[\mathrm{M}+\mathrm{NH}_{4}\right]^{+}$-adduct ions of triacylglycerols are generated, which are easily formed upon addition of the ammonium ion from ammonium acetate present in nonaqueous solutions. From this type of precursor ions, only product ions free of the ammonium ion were formed by low-energy CID utilizing a triple quadrupole instrument [11]. Major triacylglycerol product ions observed under these conditions include $\left[\mathrm{M}+\mathrm{NH}_{4}-\left(\mathrm{RCOONH}_{4}\right)\right]^{+}$-, $[\mathrm{RCO}+74]^{+}$-, and $[\mathrm{RCO}]^{+}-$ 
ions, several low-mass hydrocarbon ions originating from the fatty acid alkyl chains and the ammonium ion $(m / z 18)$. So, the only structural information obtained by this low-energy CID approach is the fatty acid composition of individual triacylglycerols. No determination of the position of individual fatty acid substituents linked to the glycerol backbone is possible. Low-energy CID of $\left[\mathrm{M}+\mathrm{NH}_{4}\right]^{+}$-precursor ions of triacylglycerols utilizing an ion trap instrument showed comparable product ions, including $[\mathrm{M}+\mathrm{H}]^{+}$-ions formed by direct loss of ammonia from the precursor ion allowing also $\mathrm{MS}^{n}$-measurements $(n=3)$ of various first generation product ions but still not enabling positional determination of fatty acid substituents [15, 19]. Triacylglycerols obtained from castor bean oil as well as some synthetic species were also analyzed as $[\mathrm{M}+\mathrm{Li}]^{+}$precursor ions by tandem mass spectrometry utilizing ion trap- [18] and triple quadrupole instrumentation [14], respectively, allowing positional isomer determination in favorable cases.

The most complete structural characterization of triacylglycerols was performed by high-energy (4 to 5 $\mathrm{keV}$ ) CID of sodiated species utilizing either a double focusing sector instrument or a tandem sector instrument $[13,17]$. Practically, all important structural features of individual triacylglycerol species with the exception of the chirality of the $s n-2$ carbon atom of the glycerol backbone, which seems to be no topic for tandem mass spectrometry, could be determined: (1) the acyl carbon number $(\mathrm{ACN})$, which represents the number of all carbon atoms of the fatty acid substituents excluding the three carbon atoms of the glycerolmoiety, (2) the number of double bonds (NDB) thus reducing the observed molecular mass by $2 \mathrm{u}$ per additional double bond in the molecule, and (3) the position of substituents (POS) distinguishing between sn-1/sn-3 substituents and the $s n-2$ substituent [17]. Based on our previous findings for product ions formed from $[\mathrm{M}+\mathrm{Na}]^{+}$-adduct ions by FAB and ESI tandem sector mass spectrometry [13], the following three groups of product ions could be observed: (1) simultaneous charge-remote fragmentations of all three fatty acid substituents including A-type ions (Scheme 1), (2) non-position-specific product ions termed as B-, C-, and D-type ions (Scheme 2), and (3) position-specific product ions known as E-, F-, G-, and J-type ions (Scheme 3). Additionally, certain fatty acid-substituents (e.g., hydroxy fatty acids, epoxy fatty acids [17]) exhibit lowmass product ions of the type $[\mathrm{RCOOH}+\mathrm{Na}]^{+}$, not observed for common fatty acids [i.e., saturated or (multiply) unsaturated fatty acids with an even number of carbon atoms] without an additional oxygen function (e.g., hydroxy, oxo, or epoxy). In contrast, this type of product ion seems to be commonly observed for all types of fatty acids when considering $[\mathrm{M}+\mathrm{Li}]^{+}$-adduct ions as precursor ions for CID $\left(\mathrm{E}_{\mathrm{LAB}}=5 \mathrm{keV}\right)$ [17].

With the demise of (tandem) sector instruments for biological applications in mass spectrometry, MALDI on an appropriate TOF/RTOF-instrument accommo-

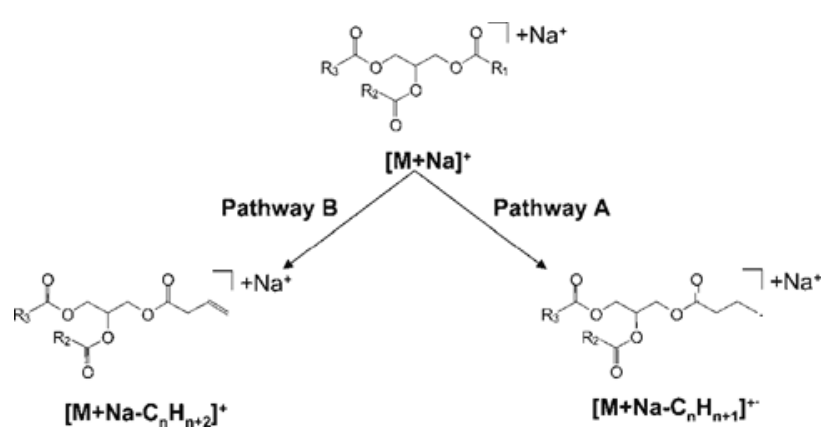

Scheme 1. High-mass charge remote fragmentation of triacylglycerol precursor ions $\left(\mathrm{Cat}^{+}=\mathrm{Na}^{+}\right.$) as observed previously from ESI-generated ions by homolytic cleavage of carbon-carbon bonds yielding distonic product ions (pathway A) and from FAB- $[12,13]$ as well as MALDI-generated ions by 1,4-elimination of molecular hydrogen plus a neutral alkene resulting in the classical closed shell product ions [41].

dates the need of sufficient resolving power, precursor ion selection, and high collision energies for the structural analysis of triacylglycerols. So far, MALDIRTOF-MS was primarily utilized in combination with PSD yielding product ion spectra with only two types of product ions, the B- and the C-type ion series [e.g., 33-35]. Only in one publication, a CID-spectrum of a synthetic triacylglycerol exhibiting poor spectral quality was shown [29]. In the present paper, we describe the complete structural analysis of $[\mathrm{M}+\mathrm{Na}]^{+}$-ions of synthetic as well as naturally occurring triacylglycerols by high-energy CID MALDI TOF/RTOF at $20 \mathrm{keV}$ collisions with helium utilizing a curved field reflectron [40]. These data constitute, to our best knowledge for the first time, the use of high-energy CID MALDI TOF/RTOF for positional isomer differentiation of neutral lipids, in this case triacylglycerols.

\section{Experimental}

\section{Chemicals}

All triacylglycerol standards, namely trilinoleoylglycerol, 1,2-dipalmitoyl-3-oleoyl-glycerol,1,3-dipalmitoyl-2-oleoylglycerol, 1,2-dioleoyl-3-palmitoyl-glycerol, 1-palmitoyl-2oleoyl-3-stearoyl-glycerol, and 1,2-distearoyl-3-oleoylglycerol were purchased from Sigma (St. Louis, MO). Simple plant-derived triacylglycerol mixtures as cocoa butter and castor bean oil were obtained from a local drug store (both of Austrian pharmacopoeia quality), Italian olive oil from a local food market (virgin oil quality). All other chemicals, including lithium, sodium, as well as potassium chloride and methanol, gradient grade for HPLC (Merck, Darmstadt, Germany), 2,4,6-trihydroxyacetophenone (Aldrich, Steinheim, Germany), and chloroform (Fluka, Buchs, Switzerland) were obtained from the mentioned commercial suppliers. 


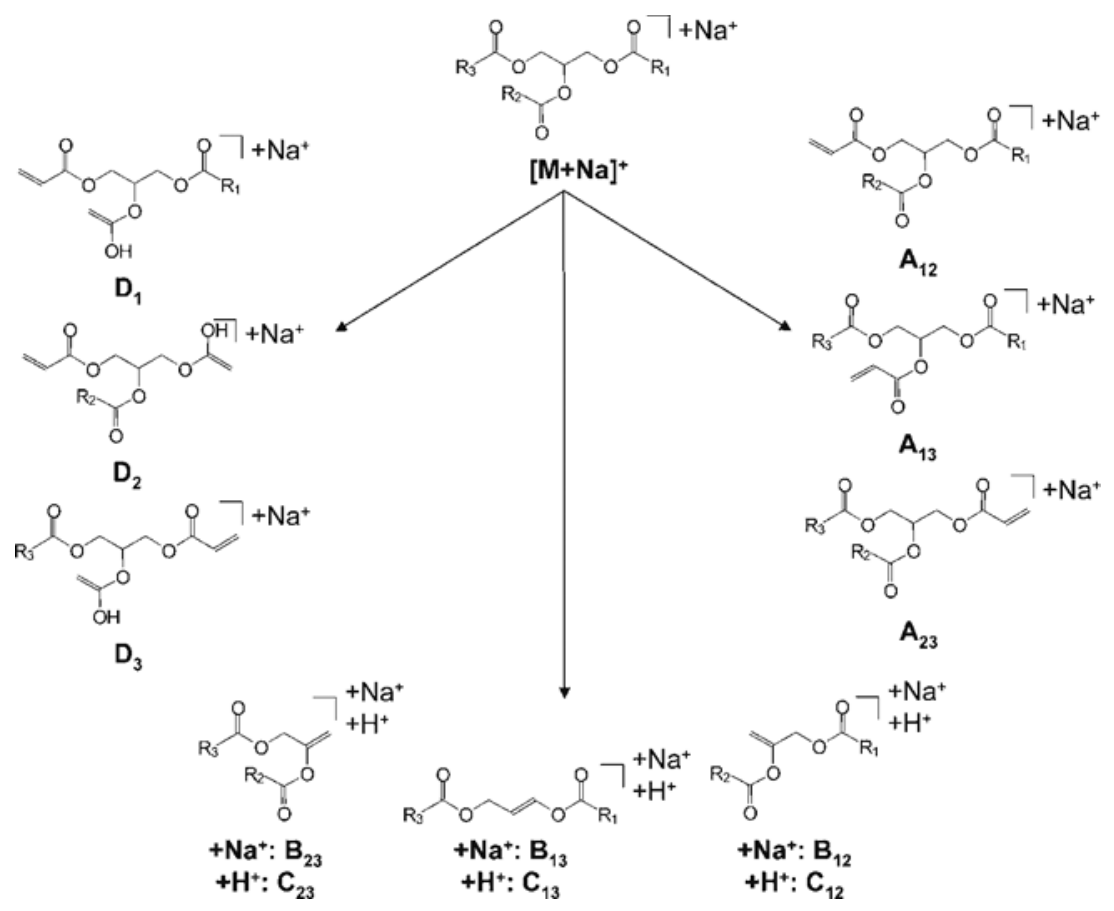

Scheme 2. Product ions of triacylglycerol precursor ions $\left(\mathrm{Cat}^{+}=\mathrm{Na}^{+}\right)$not allowing any positional determination of particular fatty acid substituent: A-ions (abundant end products of charge-remote fragmentation of fatty acid substituents), B- and C-ions (allow the determination of the fatty acid composition of individual triacylglycerols) and D-ions (the alkyl chains of two fatty acid substituents is practically lost) [13, 17].

\section{MALDI Mass Spectrometry}

All measurements were performed using a prototype Axima $\mathrm{TOF}^{2}$ MALDI time-of-flight (TOF)/reflectron
(RTOF) mass spectrometer (Shimadzu Biotech, Kratos Analytical, Manchester, UK) described in detail elsewhere [40]. Briefly, the instrument is fitted with a linear TOF analyzer as MS1 and a wide energy-acceptance

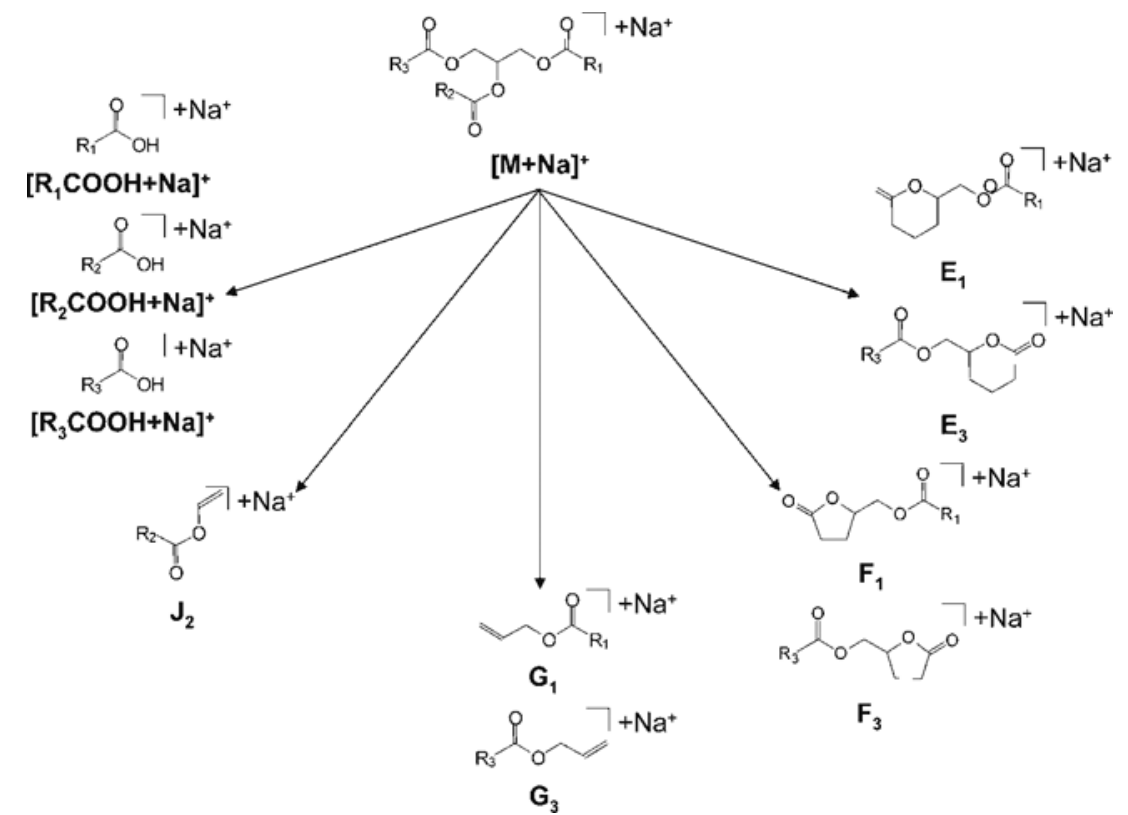

Scheme 3. Product ions of triacylglycerol precursor ions $\left(\mathrm{Cat}^{+}=\mathrm{Na}^{+}\right)$allowing positional determination of particular fatty acid substituents: E-, F-, and G-ions (only present for the sn-1 and the $\mathrm{s} n-3$ substituents) and J-ions (only present for the $s n-2$ substituent) $[13,17]$. Product ions corresponding formally to $\left[\mathrm{RCOOH}+\mathrm{Cat}^{+}\right.$are only observed with oxygen-functionalized fatty acidsubstituents in the case of Cat ${ }^{+}=\mathrm{Na}^{+}$. With $\mathrm{Li}^{+}$as cationizing species this type of product ions is generally observed for all types of fatty acid substituents [17]. 
curved field RTOF as MS2 for product ion analysis (close to $95 \%$ of the selected $\mathrm{m} / \mathrm{z}$ range), a grounded tight gas collision cell with differential pumping of the collision region and a double Bradbury-Nielsen wire ion gate for narrow mass-window precursor ion selection (4 to $6 \mathrm{u}$ at $\mathrm{m} / \mathrm{z} 900$ to 1000 as experimentally determined). An important modification compared with the commercially available instrument delivered originally was the exchange of the entire polymeric collision gas line for stainless steel tubing to keep diffusion of air, especially oxygen, into the collision gas line and, thereafter, into the CID cell to a minimum. In combination with careful purging of the gas line before measurement, these are important prerequisites to detect various types of charge-remote fragmentations typically observed at high collision energies (typically $\mathrm{E}_{\mathrm{LAB}}>2$ to $3 \mathrm{keV}$ ) as well as other high-energy fragmentations.

All triacylglycerol samples (synthetic compounds and plant-oil samples) were dissolved at $1 \mathrm{mg}$ per 1000 $\mu \mathrm{L}$ solvent (= methanol:chloroform $=7: 3, \mathrm{vol} / \mathrm{vol})$. It turned out that chloroform was superior compared to 2-propanol as solvent for dissolving the selected lipids as well as for crystallization of the final MALDI sample on the stainless steel targets. 2,4,6-Trihydroxyacetophenone was selected as MALDI-matrix for all experiments. The matrix solution was prepared by dissolving $10 \mathrm{mg}$ matrix in $1000 \mu \mathrm{L}$ methanol saturated with sodium chloride (or in the relevant experiments with lithium or potassium chloride) to avoid peak splitting of analyte ions between sodium and potassium adduct ions (the latter ones are frequently present in low abundance). For final sample preparation, analyte solution and matrix solution were mixed 1:1 (vol/vol) immediately before applying $0.8 \mu \mathrm{L}$ of the resulting mixture onto the stainless steel target surface (dried droplet preparation) yielding a final amount of $\sim 400 \mathrm{ng}$ triacylglycerol on target in case of single species samples and triacylglycerol mixture per spot in case of oil samples, respectively.

MALDI-RTOF mass spectra of triacylglycerol samples were acquired near threshold laser irradiance to avoid peak broadening of adduct ions and possible in-source fragmentation resulting in a mass spectrometric resolution of approximately 7000 to 8000 FWHM (= full width at half maximum). All displayed mass spectra were based on 500 to 1000 single and unselected laser pulses $(\lambda=337 \mathrm{~nm})$. This number of shots was acquired to obtain satisfactory ion statistics.

Post-source decay (PSD)-experiments were performed at the same laser irradiance as selected for to standard MALDI-RTOF mass spectra to keep mass resolution for product ions (typically between 600 and 1100 at FWHM depending on the observed $\mathrm{m} / \mathrm{z}$-value of the product ion) as high as possible. A total of 5000 unselected laser shots were acquired for optimum ion statistics within the PSD spectrum. Precursor ion selection was done by selecting a 4 mass unit (u)-window centered symmetrically around the monoisotopic
${ }^{12} \mathrm{C}-[\mathrm{M}+\mathrm{Na}]{ }^{+}$-triacylglycerol adduct ion of interest by the ion gate. A clear limitation of gating precursor ions even in this mass range $(<1000 \mathrm{Da})$ is the inability of complete removal of triacylglycerol species differing in their $\mathrm{m} / \mathrm{z}$ value by $2 \mathrm{u}$ (i.e., the mass difference of one double bond) yielding weak signals close to the selected precursor ion in the corresponding product ion spectra. Fortunately, due to their low abundance compared with the selected precursor ions, these co-selected precursor ions do not further contribute to the product ion spectrum significantly.

For all CID-experiments helium was introduced into the grounded gas collision cell $\left(\mathrm{E}_{\mathrm{LAB}}=20 \mathrm{keV}\right)$ at a pressure $\left(P=5 \times 10^{-6}\right.$ mbar $)$ to attenuate the selected precursor ion signal to roughly $50 \%$ of its original value. Higher helium pressures or the change from helium to heavier collision gases as, e.g., argon did not improve the quality of the CID spectra. The only important change in such CID spectra was a significant increase of low mass product ions between $\mathrm{m} / \mathrm{z} 20$ and 100 (sodium cation at $m / z 23$ and various nonspecific hydrocarbon fragments resulting from direct dissociation of fatty acid-alkyl chains). Again, a total of 5000 unselected single laser pulses was used at unchanged laser irradiance to avoid unwanted post source decay of the analyte precursor ions (grounded gas collision cell; otherwise PSD ions produced outside the CID cell would be detected at significant intensity). Typical resolution values obtained in CID spectra of sodiated triacylglycerols was 2000 to 3000 at FWHM for precursor ions and 600 to 1200 at FWHM for product ions depending on their $m / z$-values. After loading the CID calibration by the data system based on known product ion $m / z$ values of the CID spectrum of the $[\mathrm{M}+\mathrm{H}]^{+}$-ion of a synthetic peptide with the sequence $\mathrm{P}_{14} \mathrm{R}_{1}$ (Sigma, St. Louis, MO), where $\mathrm{P}$ stands for proline and $\mathrm{R}$ for arginine, all apparent product ion masses (the primary mass value as obtained by the curved field reflectron) from PSD- as well as CID spectra are shifted to their correct mass value. Finally, all spectra displayed are processed by Shimadzu Biotech Launchpad software version 2.7.0 (Shimadzu Biotech-Kratos Analytical, Manchester, UK). Background-subtraction is performed by a baseline filter width of 100 channels and spectrum smoothing was done over 5 to 7 channels by using the Savitzky-Golay method as provided by the data system software.

\section{Results and Discussion}

Triacylglycerols could be readily desorbed and ionized by MALDI as cationized species (lithiated, sodiated, potassiated) without significant in-source (prompt) fragmentation at threshold laser irradiance. No protonated or ammoniated molecules could be generated. Only at higher laser irradiance applied for analyte desorption/ionization, some in-source fragmentation became visible corresponding to alkali-containing (Btype ions) and alkali-free diglyceride fragment ions 
(C-type ions, data not shown). The mechanism of formation of this prompt fragmentation was discussed in detail by Al-Saad and colleagues, showing also the first ever recorded high-energy CID-spectrum of a sodiated triacylglycerol species by MALDI-TOF/RTOF $\left(\mathrm{E}_{\mathrm{LAB}}=\right.$ $25 \mathrm{keV}$ ) but lacking practically all important low $\mathrm{m} / \mathrm{z}$ product ions [29]. To evaluate the optimal adduct ion (lithium, sodium, or potassium) as precursor ion for high-energy CID in combination with a TOF/RTOF instrument with respect to evenly distributed (across the whole $\mathrm{m} / \mathrm{z}$ range) product ion formation the corresponding CID-spectra are displayed in Figure 1.

The CID-spectrum of the $[\mathrm{M}+\mathrm{Li}]^{+}$-adduct ion of trilinoleoylglycerol (see Figure 1a) exhibits abundant B-, $\mathrm{C}_{-}, \mathrm{G}-, \mathrm{J}-$, and $[\mathrm{RCOOH}+\mathrm{Li}]^{+}$-type product ions according to the Cheng-Gross-Pittenauer-based triacylglycerol product ion nomenclature [13]. No significant high-mass charge-remote fragmentation of the fatty acid substituents between the precursor ion and the B-type product are observed. This is in some contrast to findings obtained by ESI-MS of $[\mathrm{M}+\mathrm{Li}]^{+}$-adduct ions in combination with $\mathrm{CID} /$ linked scanning at $\mathrm{B} / \mathrm{E}=$ const. $\left(\mathrm{E}_{\mathrm{LAB}}=5 \mathrm{keV}\right)$ utilizing a double focusing magnetic sector instrument where high-mass charge remote-fragmentations of the fatty acid-alkyl chains are very prominent [17]. A serious limitation of lithium cation-attachment is given by the fact that even by the exchange of sodium chloride for lithium chloride as salt dopant the sodium adduct ion is still the dominating one. So, this technique leads to splitting the sensitivity for these analyte ions between two adduct ions separated by $16 \mathrm{Da}\left([\mathrm{M}+\mathrm{Li}]^{+}\right.$versus $\left.[\mathrm{M}+\mathrm{Na}]^{+}\right)$.
In contrast, the MALDI based CID-spectrum of the sodiated precursor ion species (see Figure 1b) displays the most informative set of product ions showing practically all ions relevant for structural elucidation (A-, B-, C-, D-, E-, F, G-', as well as J-type ions). No abundant structurally informative product ions were observed in the CID-spectrum of the $[\mathrm{M}+\mathrm{K}]^{+}$-adduct ion of trilinoleoylglycerol (see Figure 1c). Based on these findings, all further experiments were done with sodiated precursor ions of synthetic triacylglycerols and natural oil components.

To demonstrate the strong influence of the introduction of collision gas on resulting product ion spectra, the corresponding PSD-and CID-spectrum of the $[\mathrm{M}+$ $\mathrm{Na}]^{+}$-adduct ion of 1,2-dipalmitoyl-3-oleoyl-glycerol are displayed in Figure $2 \mathrm{a}$ and $\mathrm{b}$, respectively.

The PSD spectrum of the $[\mathrm{M}+\mathrm{Na}]^{+}$-adduct ion of 1,2-dipalmitoyl-3-oleoyl-glycerol only exhibits B- and C-type product ions corresponding to the loss of one free fatty acid and one sodium fatty acid carboxylate residue, respectively (see Figure 2a). For observed mass assignments of precursor as well as of product ions, Table 1 exhibits all relevant $m / z$ values.

Further, no product ions allowing distinction between the two outer fatty acid substituents (sn-1, sn-3) and the middle position ( $(n-2)$ are observed in the PSD spectrum, so the only structural information that could be obtained from this spectrum is the fatty acid composition of this triacylglycerol species. Contrary to the PSD spectrum, the $20 \mathrm{keV}$ CID spectrum of the same precursor ion yields a rich array of various structurally diagnostic product ions (see Figure 2b). As mentioned

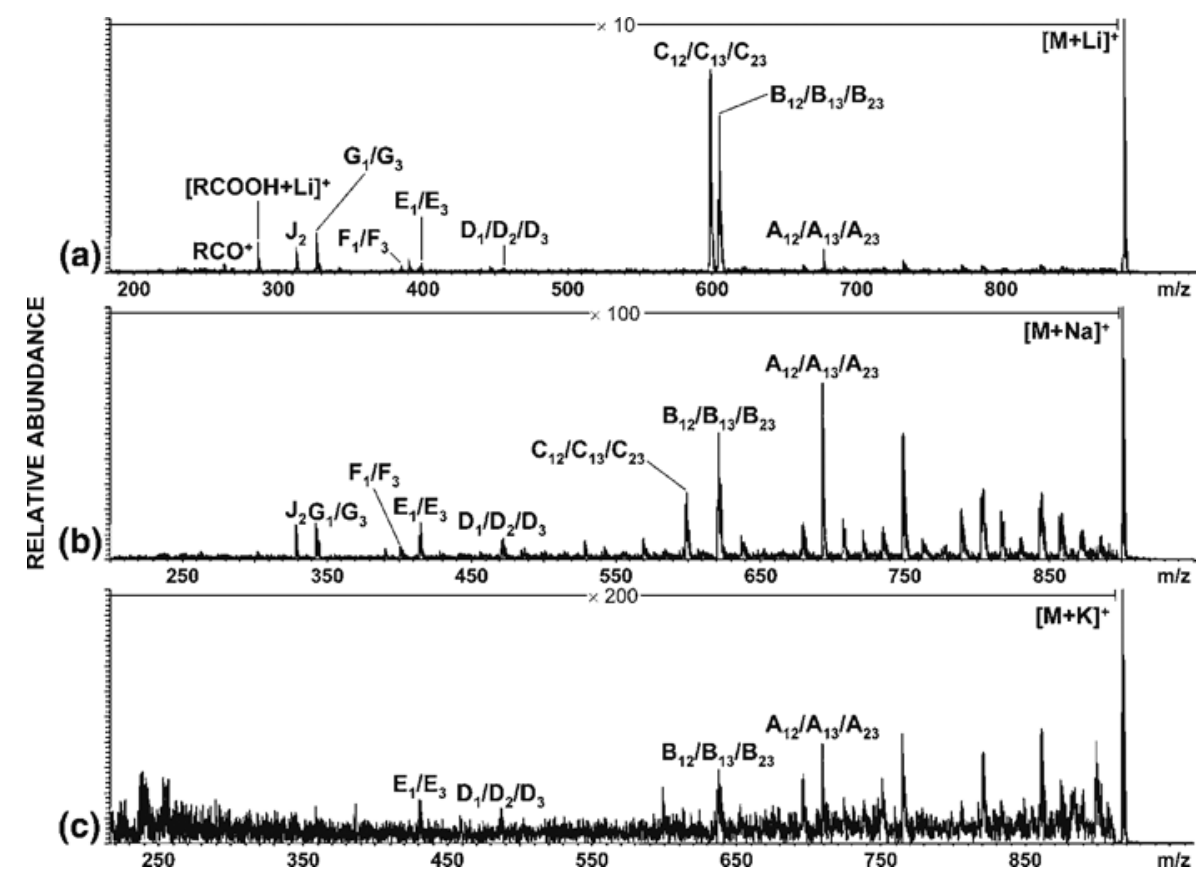

Figure 1. Evaluation of the appropriate precursor ions of triacylglycerols: MALDI high-energy CID-spectra $\left(\mathrm{E}_{\mathrm{LAB}}=20 \mathrm{keV}\right)$ of the $[\mathrm{M}+\mathrm{Li}]^{+}$-adduct ion $(\mathrm{m} / \mathrm{z} 885.8)(\mathbf{a})$, the $[\mathrm{M}+\mathrm{Na}]^{+}$-adduct ion $\left(\mathrm{m} / \mathrm{z}\right.$ 901.7) $(\mathbf{b})$, and the $[\mathrm{M}+\mathrm{K}]^{+}$-adduct ion $(\mathrm{m} / \mathrm{z}$ 917.7) $(\mathbf{c})$ of synthetic trilinoleoylglycerol. 


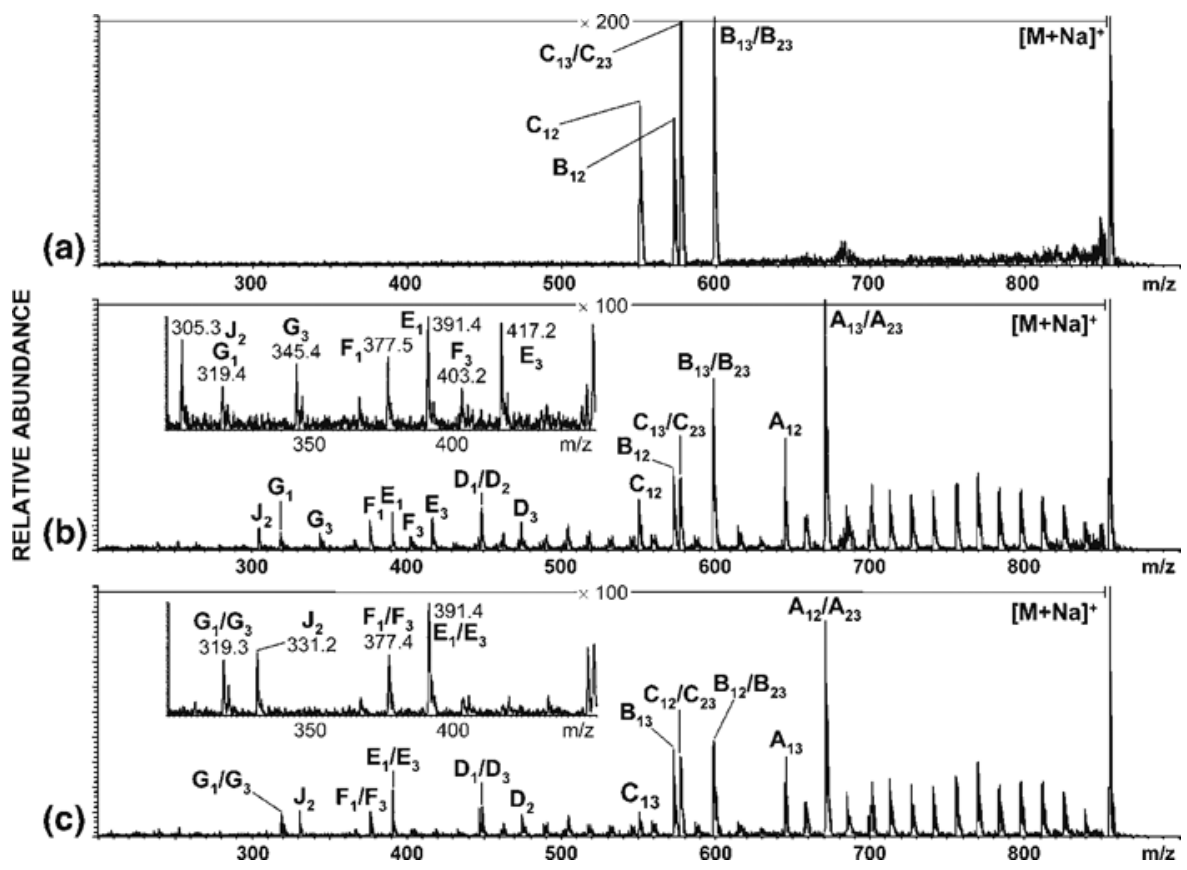

Figure 2. Triacylglycerols with two different fatty acid-substituents: MALDI PSD-spectrum of the $[\mathrm{M}+\mathrm{Na}]^{+}$-adduct ion of 1,2-dipalmitoyl-3-oleoyl-glycerol (a) and MALDI high-energy CID-spectra $\left(\mathrm{E}_{\mathrm{LAB}}=20 \mathrm{keV}\right)$ of the $[\mathrm{M}+\mathrm{Na}]^{+}$-adduct ions of the isomeric synthetic triacylglycerols 1,2dipalmitoyl-3-oleoyl-glycerol (b), and 1,3-dipalmitoyl-2-oleoyl-glycerol (all $\mathrm{m} / \mathrm{z}$ 855.7) (c). The insets in panel (b) to (c) display the $m / z$ region diagnostic for isomer distinction based on J-, G-, F-, and E-type product ions.

above, strong simultaneous charge-remote fragmentations of the three fatty acid substituents are dominating the high $\mathrm{m} / \mathrm{z}$ region of this CID spectrum. Considering the observed $\mathrm{m} / \mathrm{z}$ values, it could be concluded that the mechanism corresponds to a formal 1,4-elimination of molecular hydrogen $\left(\mathrm{H}_{2}\right)$ and loss of neutral alkenes as originally observed for FAB-based high-energy CID of fatty acids $\left(\mathrm{E}_{\mathrm{LAB}}=8 \mathrm{keV}\right)$ [41-43], recently also for MALDI-based high-energy CID of fatty acids $\left(\mathrm{E}_{\mathrm{LAB}}=1\right.$ $\mathrm{keV})$ [44] and for ESI- as well FAB-based CID of triacylglycerols $\left(\mathrm{E}_{\mathrm{LAB}}=4-8 \mathrm{keV}\right)[12,13]$. Two reviews are dealing with different mechanisms of charge-remote fragmentation, including various classes of lipids [45, 46]. Unfortunately, no unambiguous determination/ confirmation of the location of the double bond could be done due to the absence of a complete and significantly abundant series of ions related to the oleoyl substituent as all three fatty acid substituents dissociate simultaneously in this mass region. Abundant ions of the $\mathrm{A}_{-}, \mathrm{B}-$, and $\mathrm{C}_{\text {-series }}$ are detected in the middle $\mathrm{m} / \mathrm{z}$-range of this CID spectrum, the latter two types of ions yielding the fatty acid composition of this triacylglycerol species based on sodium-containing and sodiumfree product ions, respectively. The lower $\mathrm{m} / \mathrm{z}$ region between $\mathrm{m} / \mathrm{z} 300$ and 500 includes product ions of with D-series (present for all three fatty acid substituents) and the structurally important ions of the $\mathrm{E}_{1 / 3}-(\mathrm{m} / \mathrm{z}$ 417.2 and 391.4), $\mathrm{F}_{1 / 3^{-}}\left(\mathrm{m} / \mathrm{z} 403.2\right.$ and 377.5), and $\mathrm{G}_{1 / 3^{-}}$ series $(\mathrm{m} / \mathrm{z} 345.4$ and 319.4 ; all only present for $\mathrm{s} n-1$ and $\mathrm{s} n-3$ substituents), and the $\mathrm{J}_{2}$-ion $(\mathrm{m} / \mathrm{z} 305.3)$, which only formed for the sn-2 substituent (for detailed mass assignments see also Figure $2 b$, inset). Based on these low $\mathrm{m} / \mathrm{z}$ region product ions the structural isomers 1,2-dipalmitoyl-3-oleoyl-glycerol, and 1,3-dipalmitoyl2-oleoyl-glycerol exhibit strong differences in the product ion pattern (see Figure $2 b$ and $c$, insets). The structurally diagnostic ions of 1,3-dipalmitoyl-2-oleoylglycerol for the outer two fatty acid substituents are identical in mass in this case yielding $\mathrm{E}_{1 / 3}$-ions at $\mathrm{m} / \mathrm{z}$ 391.4, $\mathrm{F}_{1 / 3}$-ions at $m / z 377.4$, and $\mathrm{G}_{1 / 3}$-ions at 319.3. The $\mathrm{J}_{2}$-ion now appears at $\mathrm{m} / \mathrm{z} 331.2$, indicating the oleoyl substituent to be linked to the middle position (sn-2) at the glycerol backbone (see Figure 2c, inset). Additional examples of the usefulness of $20 \mathrm{keV}$ high-energy CID of sodiated triacylglycerol precursor ions are displayed in Figure 3, including 1,3-dioleoyl-2-palmitoyl-glycerol (Figure 3a), 1-palmitoyl-2-oleoyl-3-stearoyl-glycerol (Figure 3b), and 1,2-distearoyl-3-oleoyl-glycerol (Figure 3c).

In Figure $3 a$ the CID-spectrum of the sodiated precursor ion of 1,3-dioleoyl-2-palmitoyl-glycerol is shown. The high-mass charge remote fragmentation of the fatty acid substituents indicates indeed that a monounsaturated fatty acid substituent is present in the molecule (in this case two identical substituents) derived from the product ion group between $\mathrm{m} / \mathrm{z} 700$ and 800 (i.e., the ions at $m / z 727.7$ and 781.6 giving a mass difference of $54 \mathrm{u}$ and corresponding to the position of the double bond). The structurally diagnostic $\mathrm{E}_{1 / 3^{-}}(\mathrm{m} / \mathrm{z}$ 417.2), $\mathrm{F}_{1 / 3^{-}}(\mathrm{m} / \mathrm{z} 403.2), \mathrm{G}_{1 / 3^{-}}(\mathrm{m} / \mathrm{z} 345.4)$, and the $\mathrm{J}_{2^{-}}$ product ions $(\mathrm{m} / \mathrm{z}$ 305.1) indicate that the palmitic acid 
Table 1. Determined $\mathrm{m} / \mathrm{z}$ values of $[\mathrm{M}+\mathrm{Na}]^{+}$-adduct ions of triacylglycerols and of structurally diagnostic product ions (including $\mathrm{m} / \mathrm{z}$ values for J-, G-, F-, E-, D-, C-, and B-type product ions) of triacylglycerol species investigated and displayed in Figs. 2, 3, 5, and 6 as well as structure assignments of these triacylglycerols based on their found product ions. All $\mathrm{m} / \mathrm{z}$ values represent found values, which are all within a mass accuracy of $\pm 0.2 \mathrm{u}$ of the theoretically calculated values

\begin{tabular}{|c|c|c|c|c|c|c|c|c|}
\hline $\begin{array}{c}\text { Triacylglycerol structure } \\
\text { assignment }\end{array}$ & {$[\mathrm{M}+\mathrm{Na}]^{+}$} & $\mathrm{J}_{2}$-ion & G-ions & F-ions & E-ions & D-ions & C-ions & B-ions \\
\hline Trilinoleoylglycerol (synthetic) & 901.8 & 329.3 & $\mathbf{G}_{\mathbf{1}}: 343.4$ & $F_{1}: 401.5$ & $E_{1}: 415.4$ & $\begin{array}{l}D_{1}: 473.3 \\
D_{2}: 473.3\end{array}$ & $\begin{array}{l}\mathbf{C}_{12}: 599.7 \\
\mathbf{C}_{13}: 599.7\end{array}$ & $\begin{array}{l}\mathrm{B}_{\mathbf{1 2}}: 621.6 \\
\mathrm{~B}_{\mathbf{1 3}}: 621.6\end{array}$ \\
\hline & & & $\mathbf{G}_{3}: 343.4$ & $\mathbf{F}_{3}: 401.5$ & $E_{3}: 415.4$ & $D_{3}: 473.3$ & $C_{23}: 599.7$ & $\mathbf{B}_{\mathbf{2 3}}: 621.6$ \\
\hline $\begin{array}{l}\text { 1,2-Dipalmitoyl-3-oleoyl- } \\
\text { glycerol (synthetic) }\end{array}$ & 855.7 & 305.3 & $\mathbf{G}_{\mathbf{1}}: 319.4$ & $\mathbf{F}_{\mathbf{1}}: 377.5$ & $E_{1}: 391.4$ & $\begin{array}{l}D_{1}: 449.2 \\
D_{2}: 449.2\end{array}$ & $\begin{array}{l}C_{12}: 551.7 \\
C_{13}: 577.6\end{array}$ & $\begin{array}{l}\mathbf{B}_{12}: 573.5 \\
\mathbf{B}_{13}: 599.6\end{array}$ \\
\hline & & & $\mathbf{G}_{3}: 345.4$ & $\mathbf{F}_{3}: 403.2$ & $E_{3}: 417.2$ & $D_{3}: 475.4$ & $\mathrm{C}_{23}: 577.6$ & $\mathbf{B}_{\mathbf{2 3}}: 599.6$ \\
\hline $\begin{array}{l}\text { 1,3-Dipalmitoyl-2-oleoyl- } \\
\text { glycerol (synthetic) }\end{array}$ & 855.8 & 331.2 & $\begin{array}{l}\mathbf{G}_{\mathbf{1}}: 319.3 \\
\mathbf{G}_{\mathbf{3}}: 319.3\end{array}$ & $F_{1}: 377.4$ & $E_{1}: 391.4$ & $\begin{array}{l}D_{1}: 449.2 \\
D_{2}: 475.4 \\
D_{3}: 449.2\end{array}$ & $\begin{array}{l}\mathbf{C}_{12}: 577.6 \\
\mathbf{C}_{13}: 551.5 \\
C_{23}: 577.6\end{array}$ & $\begin{array}{l}\mathbf{B}_{\mathbf{1 2}}: 599.5 \\
\mathbf{B}_{\mathbf{1 3}}: 573.4 \\
\mathbf{B}_{3:}: 599.5\end{array}$ \\
\hline $\begin{array}{l}\text { 1,3-Dioleoyl-2-palmitoyl- } \\
\text { glycerol (synthetic) }\end{array}$ & 881.7 & 305.1 & $\mathbf{G}_{1}: 345.2$ & $F_{1}: 403.2$ & $E_{1}: 417.2$ & $\begin{array}{l}D_{1}: 475.2 \\
D_{2}: 449.3 \\
D_{3}: 475.2\end{array}$ & $\begin{array}{l}\mathbf{C}_{12}: 577.6 \\
\mathbf{C}_{13}: 603.5 \\
\mathbf{C}_{23}: 577.6\end{array}$ & $\begin{array}{l}\mathbf{B}_{12}: 599.5 \\
\mathbf{B}_{13}: 625.5 \\
\mathbf{B}_{23}: 599.2\end{array}$ \\
\hline $\begin{array}{l}\text { 1-Palmitoyl-2-oleoyl-3-stearoyl- } \\
\text { glycerol (synthetic) }\end{array}$ & 883.7 & 331.1 & $\mathbf{G}_{1}: 319.0$ & $\mathbf{F}_{\mathbf{1}}: 377.2$ & $E_{1}: 391.1$ & $\begin{array}{l}D_{1}: 449.0 \\
D_{2}: 475.1\end{array}$ & $\begin{array}{l}C_{12}: 577.3 \\
C_{13}: 579.5\end{array}$ & $\mathbf{B}_{\mathbf{1 2}}: 599.3$ \\
\hline $\begin{array}{l}\text { 1,2-Distearoyl-3-oleoyl-glycerol } \\
\text { (synthetic) }\end{array}$ & 991.9 & 333.4 & $\begin{array}{l}\mathbf{G}_{3}: 347.3 \\
\mathbf{G}_{1}: 345.3\end{array}$ & $\begin{array}{l}\mathbf{F}_{\mathbf{3}}: 405.2 \\
\mathbf{F}_{\mathbf{1}}: 403.4\end{array}$ & $\begin{array}{l}E_{3}: 419.2 \\
E_{1}: 417.4\end{array}$ & $\begin{array}{l}D_{3}: 477.3 \\
D_{1}: 477.3 \\
D_{2}: 477.3\end{array}$ & $\begin{array}{l}\mathbf{C}_{23}: 605.4 \\
\mathbf{C}_{12}: 607.8 \\
\mathbf{C}_{13}: 605.6\end{array}$ & $\begin{array}{l}\mathbf{B}_{\mathbf{2 3}}: 627.3 \\
\mathbf{B}_{\mathbf{1 2}}: 629.4 \\
\mathbf{B}_{\mathbf{1 3}}: 627.6\end{array}$ \\
\hline $\begin{array}{l}\text { 1,3-Palmitoyl-2-oleoyl-glycerol } \\
\text { (component from cocoa } \\
\text { butter) }\end{array}$ & 855.8 & 331.3 & $\begin{array}{l}\mathbf{G}_{3}: 347.4 \\
\mathbf{G}_{\mathbf{1}}: 319.3 \\
\mathbf{G}_{3}: 319.3\end{array}$ & $\begin{array}{l}\mathbf{F}_{3}: 405.5 \\
\mathbf{F}_{\mathbf{1}}: 377.3 \\
\mathbf{F}_{\mathbf{3}}: 377.3\end{array}$ & $\begin{array}{l}E_{3}: 419.4 \\
E_{1}: 391.4 \\
E_{3}: 391.4\end{array}$ & $\begin{array}{l}D_{3}: 475.1 \\
D_{1}: 449.2 \\
D_{2}: 475.3 \\
D_{3}: 449.2\end{array}$ & $\begin{array}{l}C_{23}: 605.6 \\
C_{12}: 577.7 \\
C_{13}: 551.6 \\
C_{23}: 577.7\end{array}$ & $\begin{array}{l}\mathbf{B}_{\mathbf{2 3}}: 627.6 \\
\mathbf{B}_{12}: 599.5 \\
\mathbf{B}_{13}: 573.6 \\
\mathbf{B}_{23}: 599.5\end{array}$ \\
\hline $\begin{array}{l}\text { 1-Palmitoyl-2-oleoyl-3-stearoyl- } \\
\text { glycerol (component from } \\
\text { cocoa butter) }\end{array}$ & 883.8 & 331.2 & $\mathbf{G}_{1}: 319.3$ & $F_{1}: 377.5$ & $E_{1}: 391.3$ & $\begin{array}{l}D_{1}: 449.2 \\
D_{2}: 475.2 \\
D_{2}: 477.3\end{array}$ & $\begin{array}{l}\mathbf{C}_{12}: 577.2 \\
\mathbf{C}_{13}: 579.6 \\
\mathbf{C}_{32}: 605.6\end{array}$ & $\begin{array}{l}\mathbf{B}_{12}: 599.5 \\
\mathbf{B}_{13}: 601.5 \\
\mathbf{B}_{32}: 627.6\end{array}$ \\
\hline $\begin{array}{l}\text { 1,3-Distearoyl-2-oleoyl-glycerol } \\
\text { (component from cocoa } \\
\text { butter) }\end{array}$ & 911.9 & 331.3 & $\mathbf{G}_{\mathbf{1}}: 347.3$ & $F_{1}: 405.3$ & $\mathrm{E}_{1}: 419.3$ & $\begin{array}{l}D_{1}: 477.3 \\
D_{2}: 475.3 \\
D_{3}: 477.3\end{array}$ & $\begin{array}{l}\mathbf{C}_{12}: 605.8 \\
\mathbf{C}_{13}: 607.6 \\
\mathbf{C}_{23}: 605.8\end{array}$ & $\begin{array}{l}\mathbf{B}_{12}: 627.6 \\
\mathbf{B}_{13}: 629.6 \\
\mathbf{B}_{23}: 627.6\end{array}$ \\
\hline $\begin{array}{l}\text { 1-Palmitoyl-2,3-dioleoyl- } \\
\text { glycerol (component from } \\
\text { olive oil) }\end{array}$ & 881.8 & 331.3 & $\begin{array}{l}\mathbf{G}_{1}: 319.3 \\
\mathbf{G}_{3}: 345.3\end{array}$ & $\begin{array}{l}\mathbf{F}_{\mathbf{1}}: 377.5 \\
\mathbf{F}_{\mathbf{3}}: 403.5\end{array}$ & $\begin{array}{l}E_{1}: 391.5 \\
E_{3}: 417.3\end{array}$ & $\begin{array}{l}D_{1}: 449.3 \\
D_{2}: 475.2 \\
D_{3}: 475.2\end{array}$ & $\begin{array}{l}C_{12}: 577.6 \\
C_{13}: 577.6 \\
C_{23}: 603.5\end{array}$ & $\begin{array}{l}\mathbf{B}_{\mathbf{1 2}}: 599.6 \\
\mathbf{B}_{\mathbf{1 3}}: 599.6 \\
\mathbf{B}_{\mathbf{2 3}}: 625.6\end{array}$ \\
\hline $\begin{array}{l}\text { Trioleoylglycerol (component } \\
\text { from olive oil) }\end{array}$ & 907.8 & 331.2 & $\mathbf{G}_{1}: 345.4$ & $F_{1}: 403.5$ & $E_{1}: 417.5$ & $\begin{array}{l}D_{1}: 475.3 \\
D_{2}: 475.3\end{array}$ & $\mathbf{C}_{12}: 603.7$ & $\mathbf{B}_{\mathbf{1 2}}: 625.6$ \\
\hline $\begin{array}{l}\text { Triricinoleoylglycerol } \\
\text { (component from castor } \\
\text { bean oil) }\end{array}$ & 955.7 & 347.2 & $\begin{array}{l}\mathbf{G}_{3}: 345.4 \\
\mathbf{G}_{1}: 361.2\end{array}$ & $\begin{array}{l}\mathbf{F}_{3}: 403.5 \\
\mathbf{F}_{\mathbf{1}}: 419.3\end{array}$ & $\begin{array}{l}E_{3}: 417.5 \\
E_{1}: 433.3\end{array}$ & $\begin{array}{l}D_{3}: 475.3 \\
D_{1}: 491.0 \\
D_{2}: 491.0 \\
D_{3}: 491.0\end{array}$ & $\begin{array}{l}\mathbf{C}_{23}: 603.7 \\
\mathbf{C}_{12}:- \\
\mathbf{C}_{13}:- \\
\mathbf{C}_{23}:-\end{array}$ & $\begin{array}{l}\mathbf{B}_{\mathbf{2 3}}: 625.6 \\
\mathbf{B}_{\mathbf{1 2}}: 657.4 \\
\mathbf{B}_{\mathbf{1 3}}: 657.4 \\
\mathbf{B}_{\mathbf{2 3}}: 657.4\end{array}$ \\
\hline
\end{tabular}

substituent is linked to the hydroxy group of $s n-2$ atom of the glycerol backbone. The even more complicated CID-spectrum of the $\left[\mathrm{M}+\mathrm{Na}^{+}\right.$-adduct ion of 1palmitoyl-2-oleoyl-3-stearoyl-glycerol, a triacylglycerol species with three different fatty acid substituents is exhibited in Figure 3b. The charge remote fragmentations of the fatty acid substituents do not allow any localization of the double-bond present in the molecule. From the A-, B-, and C-type product ions the fatty acid composition of the intact triacylglycerol molecule can easily be deduced. The positional distribution of the fatty acid substituents can be deduced from $\mathrm{E}_{1 / 3}-(\mathrm{m} / \mathrm{z}$ 419.2 and $\mathrm{m} / \mathrm{z} 391.1), \mathrm{F}_{1 / 3}(\mathrm{~m} / \mathrm{z} 405.2$ and $\mathrm{m} / \mathrm{z} 377.2)$, $\mathrm{G}_{1 / 3^{-}}(\mathrm{m} / \mathrm{z} 347.3$ and $\mathrm{m} / \mathrm{z} 319.0)$, and the $\mathrm{J}_{2}$-ion $(\mathrm{m} / \mathrm{z} 331.1)$. Finally, the CID spectrum of the $[\mathrm{M}+\mathrm{Na}]^{+}$-adduct ion of 1,2-distearoyl-3-oleoyl-glycerol demonstrates the resolving power for product ions separated by just $2 \mathrm{u}$ (i.e., one double bond) in the range between $\mathrm{m} / \mathrm{z} 300$ and 700 , as obtained by a reflectron flight path length of
$1.8 \mathrm{~m}$. Especially the ion types $\mathrm{E}_{1 / 3}(\mathrm{~m} / \mathrm{z} 419.4$ and 417.4), $\mathrm{F}_{1 / 3}(\mathrm{~m} / \mathrm{z} 405.5$ and $m / z 403.4), \mathrm{G}_{1 / 3}(\mathrm{~m} / z 347.4$ and $\mathrm{m} / \mathrm{z} 345.3)$, and $\mathrm{J}_{2}(\mathrm{~m} / \mathrm{z} 333.4)$ indicate that oleic acid is linked to the hydroxy group at $s n-3$ of the glycerol backbone. The double-bond position of the monounsaturated fatty acid substituent is unfortunately obscured by other charge remote fragment ions of the two stearic acid substituents for this triacylglycerol species.

Contrary to single synthetic species, triacylglycerol plant oil samples usually exhibit mixtures of triacylglycerols differing in fatty acid acyl chain length (typically constituting an even number of carbon atoms) as well as in the degree of unsaturation, making sometimes such samples rather complex. MALDI-RTOF mass spectra of relatively simple plant oil mixtures, namely the triacylglycerols of cocoa butter, olive oil, and castor bean oil exhibiting sodiated molecular ion species are shown in Figure 4, indicating that only a few lipid species are the dominating ones in these mixtures. 


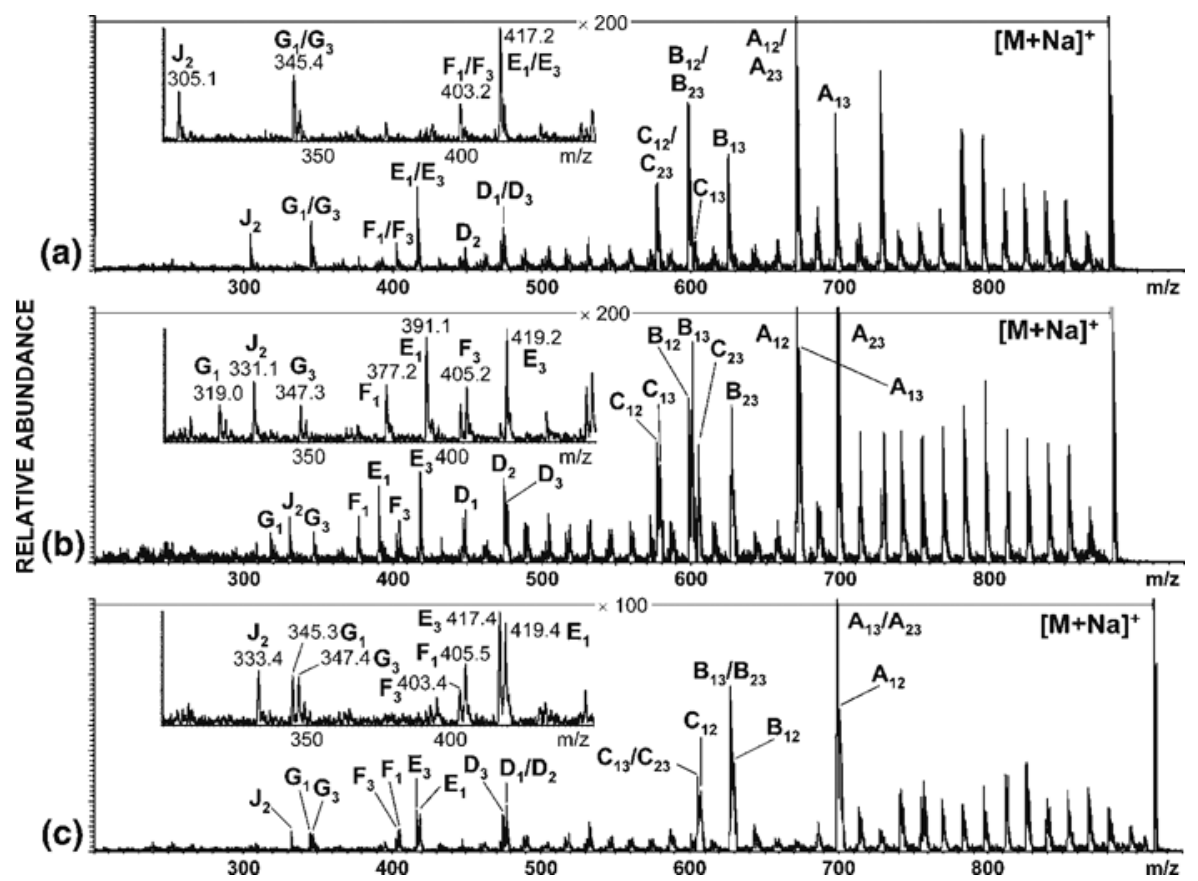

Figure 3. Triacylglycerols with two or three different fatty acid-substituents: MALDI high-energy CID-spectra $\left(\mathrm{E}_{\mathrm{LAB}}=20 \mathrm{keV}\right)$ of the $[\mathrm{M}+\mathrm{Na}]^{+}$-adduct ions of the synthetic triacylglycerols 1,3-dioleoyl-2-palmitoyl-glycerol (a), 1-palmitoyl-2-oleoyl-3-stearoyl-glycerol (b), and 1,2-distearoyl3-oleoyl-glycerol (c). The insets in panel (a) to (c) display the $\mathrm{m} / \mathrm{z}$ region diagnostic for isomer distinction based on J-, G-, F-, and E-type product ions.

The three principal triacylglycerol components of cocoa butter (ions at $m / z$ 855.8, 883.8, and 911.9) displayed in Figure 4a were further selected for high- energy CID MALDI-TOF/RTOF experiments $\left(\mathrm{E}_{\mathrm{LAB}}=\right.$ $20 \mathrm{keV}$ ) to prove the validity of the above discussed dissociation behaviors of synthetic sodiated triacylglycerol

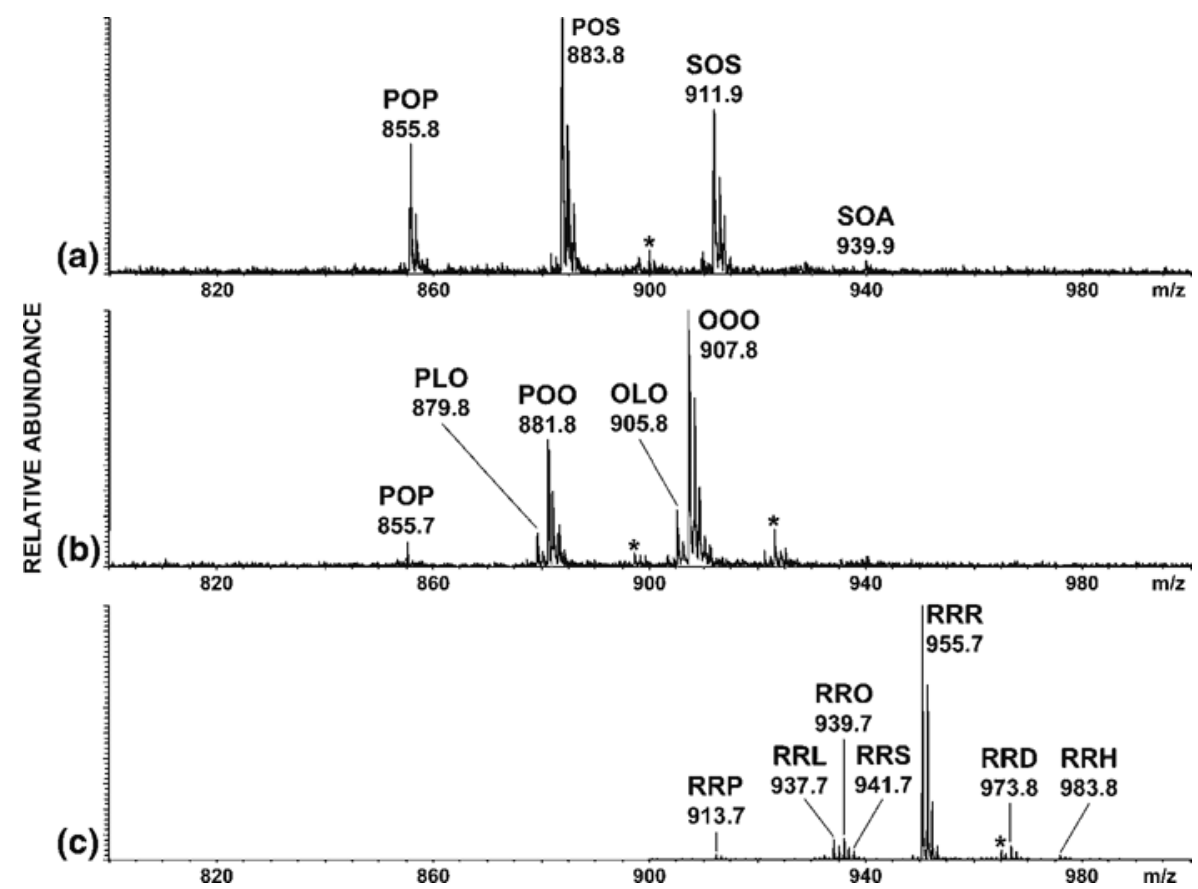

Figure 4. MALDI-RTOF mass spectra of the $[\mathrm{M}+\mathrm{Na}]^{+}$-adduct ion region of the triacylglycerols of cocoa butter (a), Italian olive oil (b), and castor bean oil (c). Asterisks $\left(^{*}\right)$ display natural traces of $[\mathrm{M}+\mathrm{K}]^{+}$-adduct ions of triacylglycerols. Abbreviations used: $\mathrm{D}=$ non-specified dihydroxystearic acid, $\mathrm{H}=$ non-specified dihydroxyeicosenoic acid, $\mathrm{L}=$ linoleic acid, $\mathrm{O}=$ oleic acid, $\mathrm{P}=$ palmitic acid, $\mathrm{R}=$ ricinoleic acid. 


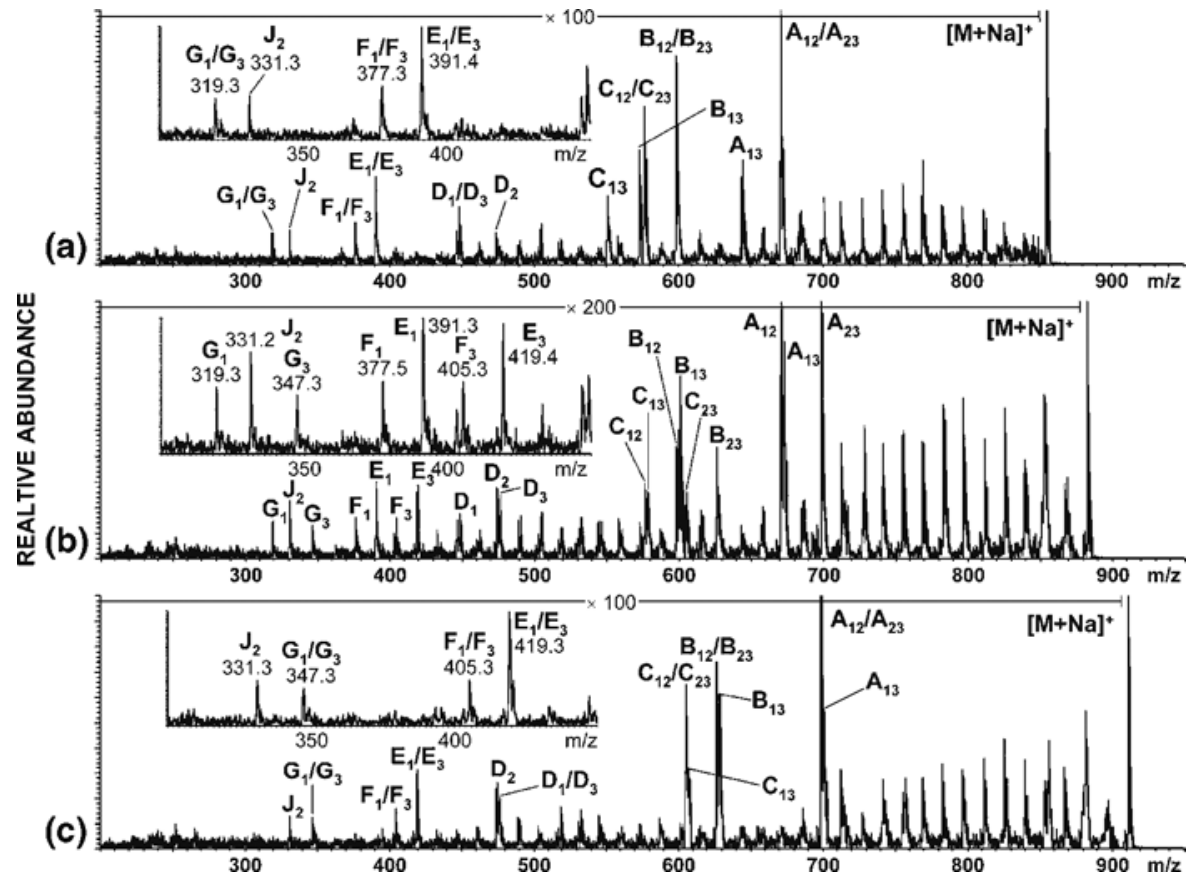

Figure 5. MALDI high-energy CID spectra $\left(\mathrm{E}_{\mathrm{LAB}}=20 \mathrm{keV}\right)$ of selected $[\mathrm{M}+\mathrm{Na}]^{+}$-adduct ions of triacylglycerols from cocoa butter at $\mathrm{m} / \mathrm{z}$ 855.7: 1,3-dipalmitoyl-2-oleoyl-glycerol (a), at $\mathrm{m} / \mathrm{z}$ 883.8: 1-palmitoyl-2-oleoyl-3-stearoyl-glycerol (b), and at $\mathrm{m} / \mathrm{z}$ 911.9: 1,3-distearoyl-2-oleoyl-glycerol (c). The insets in panel (a) to (c) display the $\mathrm{m} / \mathrm{z}$ region diagnostic for isomer distinction based on J-, $\mathrm{G}-, \mathrm{F}$ - and E-type product ions.

precursor ions for "real-life" samples. Considering the precursor ion at $\mathrm{m} / \mathrm{z} 855.8$, it immediately turned out that this ion shares the same molecular weight and the same fatty acid composition with the two synthetic isomeric triacylglycerol species 1,2-dipalmitoyl-3oleoyl-glycerol and 1,3-dipalmitoyl-2-oleoyl-glycerol, already shown in Figure $2 \mathrm{~b}$ and $\mathrm{c}$. Comparing these CID spectra with that obtained from the cocoa butter component, it is evident that the spectrum displayed in Figure 2c and Figure 5a are practically identical with special emphasis on the low- $m / z$ region were the characteristic product ions for isomer differentiation (J-, G-, F-, and E-type ions) are detected (see also mass lists of compounds 3 and 7 in Table 1.).

Based on these data, the structural identity of this cocoa butter component detected at $\mathrm{m} / \mathrm{z} 855.8$ is $1,3-$ dipalmitoyl-2-oleoyl-glycerol. The same strategy for structural identification for the second major cocoa butter component detected at $\mathrm{m} / \mathrm{z} 883.8$ could be followed by comparing the CID-spectrum of synthetic 1-palmitoyl-2-oleoyl-3-stearoyl-glycerol shown in Figure $3 \mathrm{~b}$ with the CID-spectrum of the cocoa butter in Figure $5 \mathrm{~b}$ (see again the $\mathrm{m} / \mathrm{z}$ list of triacylglycerol compounds in Table 1.). All structurally diagnostic product ions in both spectra have the same $\mathrm{m} / \mathrm{z}$ values, so it can be concluded that both triacylglycerols have the identical structure. In case of the third main cocoa butter component detected at $\mathrm{m} / \mathrm{z}$ 911.9, the CIDspectrum of the $[\mathrm{M}+\mathrm{Na}]^{+}$-adduct ion of synthetic triacylglycerol 1,2-distearoyl-3-oleoyl-glycerol differs significantly in the $\mathrm{m} / \mathrm{z}$ region between $\mathrm{m} / \mathrm{z} 300$ and 450 , the region where structurally diagnostic J-, G-, F-, and E-type ions are detected. As the corresponding $\mathrm{J}_{2}$-ions differ by $2 \mathrm{u}$ between both CID-spectra $(\mathrm{m} / \mathrm{z} 333.4$ for 1,2-distearoyl-3-oleoyl-glycerol and $\mathrm{m} / \mathrm{z} 331.3$ for the cocoa butter component) the fatty acid-substituent linked to the hydroxy group of the sn-2 atom of the glycerol backbone was elucidated as oleic acid in case of the cocoa butter triacylglycerol. Therefore, the two triacylglycerol (1,2-distearoyl-3-oleoyl-glycerol and 1,3distearoyl-2-oleoyl-glycerol) are simply positional isomers, the natural one corresponding to 1,3-distearoyl-2oleoyl-glycerol (see Table 1 for detailed $\mathrm{m} / \mathrm{z}$ assignments).

Another pair of positional isomers of triacylglycerols is shown in Figure 3a (the CID-spectrum of the [M+ $\mathrm{Na}]^{+}$-adduct ion of synthetic 1,3-dioleoyl-2-palmitoylglycerol) and Figure 6a (the CID-spectrum of the [M + $\mathrm{Na}$ ]+-adduct ion of an olive oil component with an $\mathrm{m} / \mathrm{z}$ valueof 881.9 ).

Comparing the $\mathrm{m} / \mathrm{z}$ values of the product ions of both compounds displayed in Table 1, (Compounds 4 and 10) it becomes clear that the natural olive oil component is a simple positional isomer of the synthetic one based on $m / z$ values of the E-, F-, G-, and J-type ions. So it can be concluded that the structure of this plant oil component is 1-palmitoyl-2,3-dioleoyl-glycerol.

Finally, the CID-spectra of the $[\mathrm{M}+\mathrm{Na}]^{+}$-adduct ion of two natural oil components, trioleoyl-glycerol from olive oil and tri ricinoleoyl-glycerol (ricinoleic acid $=12$-hydroxy-octadec-9Z-enoic acid) are dis- 


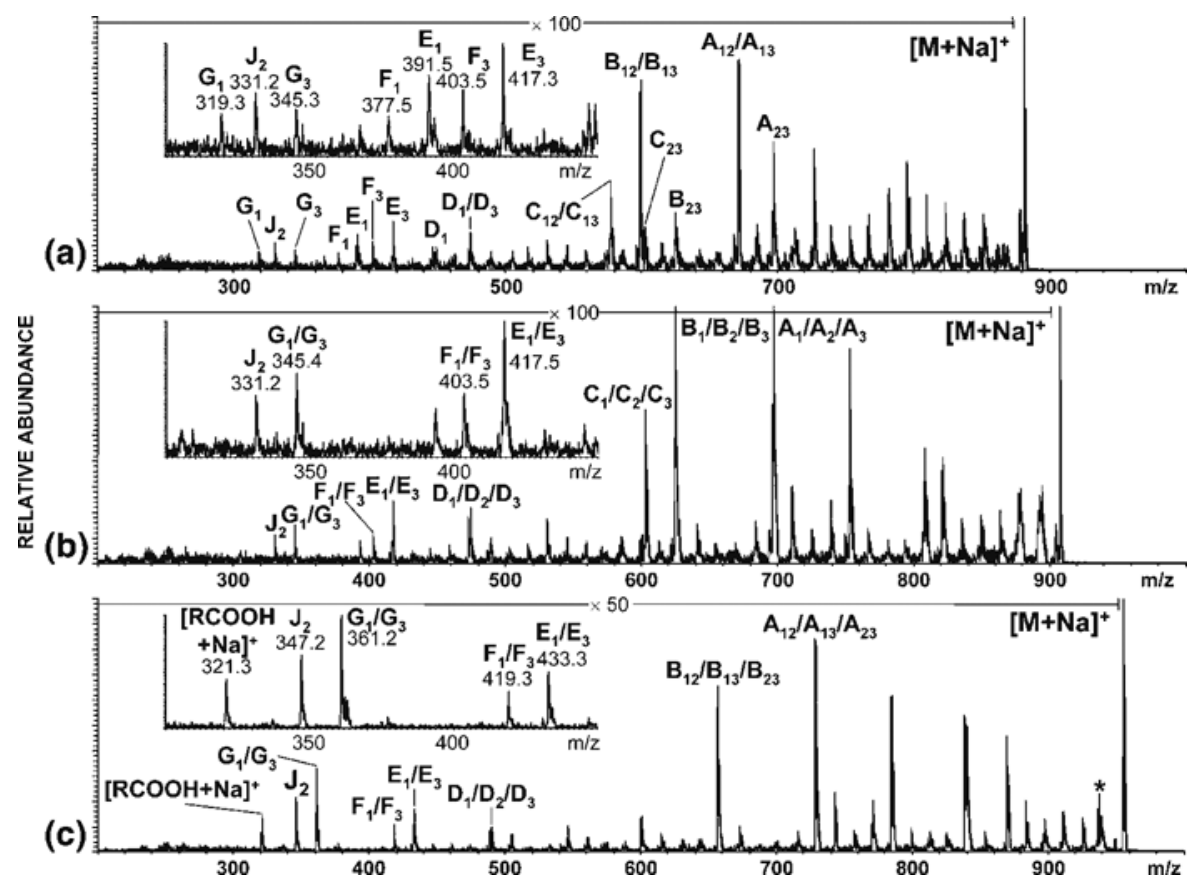

Figure 6. MALDI high-energy CID spectra $\left(\mathrm{E}_{\mathrm{LAB}}=20 \mathrm{keV}\right)$ of selected $[\mathrm{M}+\mathrm{Na}]^{+}$-adduct ions of triacylglycerols of Italian olive oil at $\mathrm{m} / \mathrm{z}$ 881.8: 1-palmitoyl-2,3-dioleoyl-glycerol (a), at $\mathrm{m} / \mathrm{z}$ 907.8: trioleoylglycerol (b), and of castor bean oil at $\mathrm{m} / \mathrm{z}$ 955.7: triricinoleoylglycerol (c). The insets in panel (a) to (c) display the $m / z$ region diagnostic for isomer distinction based on J-, G-, F-, and E-type product ions. An asterisk $\left(^{*}\right)$ in (c) indicates water loss from the precursor ion.

played in Figure $6 \mathrm{~b}$ and $\mathrm{c}$. As all three fatty acid substituents within each compound are identical all high-mass A-, B-, and C-type (this one only present for trioleoyl-glycerol) product ions share the same $\mathrm{m} / \mathrm{z}$ values as displayed in Figure $6 \mathrm{~b}$ and c, respectively. Therefore also the charge-remote fragmentations of the fatty acid substituents yield only one series of ions, thus allowing double bond location and in the case of triricinoleoylglycerol also location of the hydroxy modification of the fatty acid-alkyl chain.

\section{Conclusion}

MALDI-produced [ $\mathrm{M}+\mathrm{Na}]^{+}$-adduct ions of triacylglycerols were demonstrated for the first time to be useful in positional isomer differentiation by "true" high-energy CID TOF/RTOF experiments $\left(\mathrm{E}_{\mathrm{LAB}}=20 \mathrm{keV}\right)$, thus substituting previous popular (tandem) sector instrumentation for structural investigations (therefore we are talking from a renaissance). Characteristic ions were formed upon high-energy CID at $\mathrm{E}_{\mathrm{LAB}}=20 \mathrm{keV}$ and mass-analyzed by a curved-field reflectron TOF instrument (MS2) showing abundant charge-remote fragmentations of the fatty acid-substituents (including the A-type ions and formed through 1,4-elimination of molecular hydrogen as reported previously for FAB-produced precursor ions [12]), product ions containing two fatty acid-substituents (B- and C-type ions determining the fatty acid composition of a given triacylglycerol) and product ions containing one fatty acid-substituent (D-, E-, F- G-, and J-type ions). Especially the last three types of product ions allowed positional isomer differentiation based on specific fragmentation mechanisms for either the $s n-1 / s n-3$ substituents or the $s n-2$ substituent. This allows full structure elucidation also of simple natural triacylglycerol mixtures with the exception of the chirality at the $s n-2$ atom of the glycerol backbone. Double bond and hydroxy group localization could be determined in favorable cases (i.e., sufficient $\mathrm{S} / \mathrm{N}$ ratios of high $\mathrm{m} / \mathrm{z}$ range fragment ions). A limitation for triacylglycerol analysis by high-energy CID MALDI TOF/RTOF-MS was given by the fact that current precursor ion selection by ion gating (used by all vendors) was limited to a mass window of $4 \mathrm{u}$, making it difficult or maybe impossible to analyze triacylglycerols separated only by one double bond (i.e., $\mathrm{m} / \mathrm{z}$ value difference of $2 \mathrm{u}$ ). An LC/MALDI-MS/MS approach could solve the latter problem of precursor ion signals spaced only by just $2 \mathrm{u}$ while keeping the ability to perform high-energy CID for almost complete structural elucidation of triacylglycerols as it is necessary in lipidomics or plant oil research.

\section{References}

1. Byrdwell, W. C.; Emken, E. A. Analysis of triglycerides using atmospheric pressure chemical ionization mass spectrometry. Lipids 1995, 30, $173-175$.

2. Neff, W. E.; Byrdwell, W. C. Soybean oil triacylglycerol analysis by reversed-phase high-performance liquid chromatography coupled with atmospheric pressure chemical ionization mass spectrometry. J. Am. Oil Chem. Soc. 1995, 72, 1185-1191.

3. Neff, W. E.; Byrdwell, W. C. Triacylglycerol analysis by high performance liquid chromatography-atmospheric pressure chemical ioniza- 
tion mass spectrometry: Crepis alpina and Vernonia galamensis seed oils. J. Liquid Chromatogr. 1995, 18, 4165-4181.

4. Byrdwell, W. C.; Neff, W. E. Analysis of genetically modified canola varieties by atmospheric pressure chemical ionization mass spectrometry and flame ionization detection. J. Liquid Chromatogr. Rel. Technol. $1996,19,2203-2225$.

5. Laakso, P.; Voutilainen, P. Analysis of triacylglycerols by silver-ion high-performance liquid chromatography-atmospheric pressure chemical ionization. Lipids 1996, 31, 1311-1322.

6. Mottram, H. R.; Evershed, R. P. Structure analysis of triacylglycerol positional isomers using atmospheric pressure chemical ionization mass spectrometry. Tetrahedron Lett. 1996, 37, 8593-8596.

7. Byrdwell, W. C.; Emken, E. A.; Neff, W. E.; Adlof, R. O. Quantitative analysis of triglycerides using atmospheric pressure chemical ionizationmass spectrometry. Lipids 1996, 31,919-935.

8. Byrdwell, W. C. Atmospheric pressure chemical ionization mass spectrometry for the analysis of lipids. Lipids 2001, 36, 327-346.

9. Byrdwell, W. C.; Neff, W. E. Dual parallel electrospray ionization and atmospheric pressure chemical ionization mass spectrometry (MS), MS/MS and MS/MS/MS for the analysis of triacylglycerols and triacylglycerol oxidation products. Rapid Commun. Mass Spectrom. 2002, $16,300-319$

10. Xu, Y.; Brenna, J. T. Atmospheric pressure covalent adduct chemical ionization tandem mass spectrometry for double bond location in monoene- and diene-containing triacylglycerols. Anal. Chem. 2007, 79, 2525-2536.

11. Duffin, K. L.; Henion, J. D.; Shieh, J. J. Electrospray and tandem mass spectrometric characterization of acylglycerol mixtures that are dissolved in nonpolar solvents. Anal. Chem. 1991, 63, 1781-1788.

12. Cheng, C.; Pittenauer, E.; Gross, M. L. Charge-remote fragmentations are energy-dependent processes. J. Am. Soc. Mass Spectrom. 1998, 9, 840.

13. Cheng, C.; Gross, M. L.; Pittenauer, E. Complete structural elucidation of triacylglycerols by tandem sector mass spectrometry. Anal. Chem. 1998, 70, 4417-4426.

14. Hsu, F.-F.; Turk, J. Structural characterization of triacylglycerols as lithiated adducts by electrospray ionization mass spectrometry using low-energy collisionally activated dissociation on a triple quadrupole instrument. J. Am. Soc. Mass Spectrom. 1999, 10, 587-599.

15. Marzilli, L. A.; Fay, L. B.; Dionisi, F.; Vouros, P. Structural characterization of triacylglycerols using electrospray ionization- $\mathrm{MS}^{\mathrm{n}}$ ion-trap MS. J. Am. Oil Chem. Soc. 2003, 80, 195-202.

16. $\mathrm{Wu}, \mathrm{Z}$.; Rodgers, R. P.; Marshall, A. G. Characterization of vegetable oils: Compositional fingerprints derived from electrospray ionization Fourier-transform ion cyclotron resonance mass spectrometry. J. Agric. Food Chem. 2004, 52, 5322-5328.

17. Pittenauer, E.; Welz, W. Free Fatty Acids and Triacylglycerols. In The Encyclopedia of Mass Spectrometry, Vol. III, Biological Applications Part A: Carbohydrates, Nucleic Acids, and other Biological Compounds, Gross, M. L., Caprioli, R. M., Eds.; Elsevier: Oxford, UK, 2005; p. 397-415.

18. Lin, J.-T.; Arcinas, A. Regiospecific analysis of diricinoleoylglycerols in castor (Ricinus communis L.) oil by electrospray ionization-mass spectrometry. J. Agric. Food Chem. 2007, 55, 2209-2216.

19. McAnoy, A. M.; Wu, C. C.; Murphy, R. C. Direct qualitative analysis of triacylglycerols by electrospray mass spectrometry using a linear ion trap. J. Am. Soc. Mass Spectrom. 2005, 16, 1498-1509.

20. Murphy, R. C.; James, P. F.; McAnoy, A. M.; Krank, J.; Duchoslav, E.; Barkley, R. M. Detection of the abundance of diacylglycerol and triacylglycerol molecular species in cells using neutral loss mass spectrometry. Anal. Biochem. 2007, 366, 59-70.

21. Barber, M.; Tetler, L. W.; Bell, D.; Ashcroft, A. E.; Brown, R. S.; Moore, C. Applications of a continuous flow probe in FAB mass spectrometry. Org. Mass Spectrom. 1987, 22, 647-650.

22. Evans, C.; Traldi; Bambagiotti-Alberti, M.; Gianellini, V.; Coran, S. A.; Vincieri, F. F. Positive and negative fast atom bombardment mass spectrometry and collision spectroscopy in structural characterization of mono-, di-, and triglycerides. Biol. Mass Spectrom. 1991, 20, 351-356.

23. Hori, M.; Sahashi, Y.; Koike, S.; Yamaoka, R.; Sato, M. Molecular species analysis of polyunsaturated fish triacylglycerol by high performance liquid chromatography/fast atom bombardment mass spectrometry. Anal. Sci. 1994, 10, 719-724.

24. Lamberto, M.; Saitta, M. Principal component analysis in fast atom bombardment-mass spectrometry in edible oils. J. Am. Oil. Chem. Soc. 1995, 72, 867-871.

25. Kim, Y. H.; Han, S.-Y.; Cho, S.-H.; Yoo, J. S.; Jhon, G.-J. Structural determination of synthetic monoacetyldiglycerides by tandem mass spectrometry of sodium-adducted molecules. Rapid Commun. Mass Spectrom. 1999, 13, 481-487.

26. Kim, H. K.; So, K.-Y.; Limb, J.-K.; Jhon, G.-J.; Han, S.-Y. Identification of short-chain fatty acids at $s n-2$ and $s n-3$-positions from bovine udder by fast atom bombardment mass spectrometry. Rapid Commun. Mass Spectrom. 2000, 14, 2230-2237.

27. Pittenauer, E.; Allmaier, G.; Schmid, E. R. Rapid molecular mass determination of mon-, di-, and triglycerides by californium-252 plasma desorption mass spectrometry using 3-(3-pyridyl)acrylic acid as matrix. Org. Mass Spectrom. 1994, 29, 108-111.

28. Zöllner, P.; Stübiger, G.; Schmid, E.; Pittenauer, R.; Allmaier, G. MALDI mass spectrometry of biomolecules and synthetic polymers using alkali hexacyanoferrate (II) complexes and glycerol as matrix. Int. J. Mass Spectrom. Ion Processes 1997, 169/170, 99-107.

29. Asbury, G. R.; Al-Saad, K.; Siems, W. F.; Hannan, R. M.; Hill, H. H. Jr. Analysis of triacylglycerols and whole oils by matrix-assisted laser desorption/time of flight mass spectrometry. J. Am. Soc. Mass Spectrom. 1999, 10, 983-991.

30. Ayorinde, F. O.; Elhilo, E.; Hlongwane, C. Matrix-assisted laser desorption/ionization time-of-flight mass spectrometry of canola, castor, and olive oil. Rapid Commun. Mass Spectrom. 1999, 13, 737-739.

31. Ayorinde, F. O.; Eribo, B. E.; Balan, K. V.; Johnson, J. H. Jr.; Wan, L. W. Determination of major triacylglycerol components of polyunsaturated specialty oils using matrix-assisted laser desorption time-of-flight mass spectrometry. Rapid Commun. Mass Spectrom. 1999, 13, 937-942.

32. Ayorinde, F. O.; Keith, Q. L. Jr.; Wan, L. W. Matrix-assisted laser desorption/ionization time-of-flight mass spectrometry of cod liver oil and the effect analyte/matrix concentration on signal intensities. Rapid Commun. Mass Spectrom. 1999, 13, 1762-1769.

33. Ayorinde, F. O.; Elhilo, E.; Hlongwane, C.; Saeed, K. Matrix-assisted laser desorption/ionization time-of-flight mass spectrometry of Vernonia galamensis oil. J. Am. Oil. Chem. Soc. 1999, 76, 1217-1221.

34. Stübiger, G.; Pittenauer, E.; Allmaier, G. Characterization of castor oil by on-line and off-line non-aqueous high-performance liquid chromatography-mass spectrometry (APCI and UV/MALDI). Phytochem. Anal. 2003, 14, 337-346.

35. Al-Saad, K. A.; Zabrouskov, V.; Siems, W. F.; Knowles, N. R.; Hannan R. M.; Hill, H. H. Jr. Matrix-assisted laser desorption time-of-flight mass spectrometry of lipids: Ionization and prompt fragmentation. Rapid Commun. Mass Spectrom. 2003, 17, 87-96.

36. Lay, J. O. Jr.; Liyanage, R.; Durham, B.; Brooks, J. Rapid characterization of edible oils by direct matrix-assisted laser desorption time-of-flight mass spectrometry analysis of triacylglycerols. Rapid Commun. Mass Spectrom. 2006, 20, 952-958

37. Stübiger, G.; Belgacem, O. Analysis of Lipids using 2,4,6trihydroxyacetophenone as a matrix for MALDI mass spectrometry. Anal. Chem. 2007, 79, 3206-3213.

38. Kaufmann, M.; Wiesman, Z. Pomegranate oil analysis with emphasis on MALDI-TOF/MS triacylglycerol fingerprinting. J. Agric. Food Chem. 2007, 55, 10405-10413.

39. Pittenauer, E., Allmaier, G. High-energy collision-induced dissociation of biomolecules by means of MALDI-TOF/RTOF mass spectrometry in comparison to tandem sector mass spectrometry. Comb. Chem. High Throughput Screen. 2009, 12, 137-155.

40. Belgacem, O.; Bowdler, A.; Brookhouse, I.; Brancia, F. L.; Raptakis, E. Dissociation of biomolecules using a ultraviolet matrix-assisted laser desorption/ionization time-of-flight/curved field reflectron tandem mass spectrometer equipped with a differential-pumped collision cell. Rapid Commun. Mass Spectrom. 2006, 20, 1653-1660.

41. Tomer, K. B.; Crow, F. W.; Gross, M. L. Location of double-bond position in unsaturated fatty acids by negative ion MS/MS. J. Am. Chem. Soc. 1983, 105, 5487-5488.

42. Claeys, M.; Nizigiyimana, L.; Van den Heuvel, H.; Derrick, P. J. Mechanistic aspects of charge-remote fragmentation in saturated and mono-unsaturated fatty acid derivatives. Rapid Commun. Mass Spectrom. 1996, 10, 770-774.

43. Huysmans, L.; Nizigiyimana, L.; Van den Heuvel, H.; Claeys, M. Charge-remote molecular hydrogen removal in protonated and alkalicationized long-chain fatty acid esters upon cesium ion bombardment. Int. J. Mass Spectrom. 1999, 188, 39-52.

44. Trimpin, S.; Clemmer, D. E.; McEwen, C. N. Charge-remote fragmentation of lithiated fatty acids on a TOF-TOF using matrix-ionization. J. Am. Soc. Mass Spectrom. 2007, 18, 1967-1972.

45. Cheng, C.; Gross, M. L. Applications and mechanisms of charge-remote fragmentation. Mass Spectrom. Rev. 2000, 19, 398-420.

46. Gross, M. L. Charge-remote fragmentation: An account of research on mechanisms and applications. Int. J. Mass Spectrom. 2000, 200, 611-624. 